
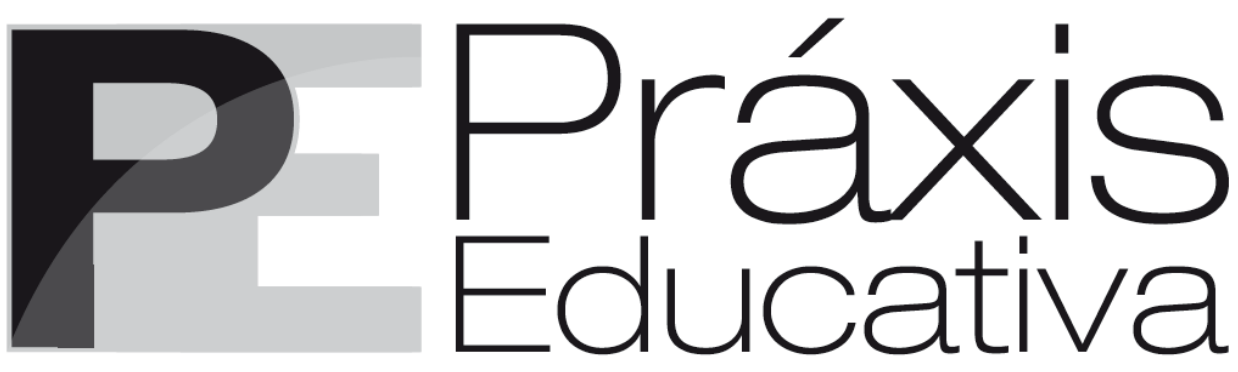

ISSN 1809-4031

elSSN 1809-4309

https://doi.org/10.5212/PraxEduc.v.16.16612.036

\title{
Contribuições de Paulo Freire na Educação do Campo: formação de professores/as e o ensino de Ciências
}

\section{Paulo Freire's contributions to the Countryside Education: teacher training and Science teaching}

\section{Contribuciones de Paulo Freire en la Educación del Campo: formación de docentes y la enseñanza de Ciencias}

\author{
Adalberto Penha de Paula* \\ iD https://orcid.org/0000-0002-9906-3989 \\ Roberto Gonçalves Barbosa ${ }^{* *}$ \\ iD http://orcid.org/0000-0002-0397-4754
}

\begin{abstract}
Resumo: Este trabalho expõe uma reflexão a respeito do pensamento teórico e metodológico do educador brasileiro Paulo Freire no âmbito da Educação do Campo e de suas contribuições para o processo de formação de professoras/es de Ciências da Natureza. Com esse objetivo, tomou-se como referência o curso de Licenciatura em Educação do Campo da Universidade Federal do Paraná - Setor Litoral, a partir do qual se apresentam os princípios e as influências históricas, filosóficas, sociais e práticas que conduziram à implantação de cursos dessa natureza nas universidades públicas nacionais. Metodologicamente, trata-se de um estudo teórico, mas também conta com evidências empíricas de práticas educacionais já realizadas. Dentre as reflexões finais, destaca-se a importância da pedagogia freiriana como uma pedagogia contrahegemônica e balizadora para a educação dos povos do campo, das águas e das florestas.

Palavras-chave: Pensamento freiriano. Formação de professoras/es do campo. Educação científica.
\end{abstract}

Abstract: This work presents a reflection on the theoretical and methodological thinking of the Brazilian educator Paulo Freire in the field of the Countryside Education and his contributions to the process of training teachers of Natural Sciences. With this objective, the Pre-service teacher education courses of the Countryside Education at the Federal University of Paraná - Coastal Sector was taken as a reference, from which the historical, philosophical, social and practical principles and influences that led to the implantation

\footnotetext{
* Professor na Universidade Federal do Paraná (UFPR) - Setor Litoral no curso de Licenciatura em Educação do Campo - Ciências da Natureza. Doutor em Educação (UFPR). E-mail:<adalbertoppenha@gmail.com>.

** Professor na Universidade Federal do Paraná (UFPR) - Setor Litoral no curso de Licenciatura em Educação do Campo - Ciências da Natureza. Doutor em Ensino de Ciências e Educação Matemática (UEL). E-mail: <robertobarbosa@ufpr.br>.
} 
of courses of this nature at national public universities are presented. Methodologically, it is a theoretical study, but it also has empirical evidence of educational practices already carried out. Among the final reflections, the importance of Freire's pedagogy stands out as a counter-hegemonic and guiding pedagogy for the education of the people from the rural areas, waters and forests.

Keywords: Freirean thinking. Training of countryside teachers. Scientific education.

Resumen: Este trabajo expone una reflexión respecto del pensamiento teórico y metodológico del educador brasileño Paulo Freire en el ámbito de la Educación del Campo y de sus contribuciones al proceso de formación de docentes de Ciencias Naturales. Con este objetivo, se tomó como referencia la carrera de Licenciatura en Educación del Campo de la Universidad Federal de Paraná - Sector Litoral, Brasil, a partir del cual se presentan los principios y las influencias históricas, filosóficas, sociales y prácticas que llevaron a la implementación de las carreras de esta naturaleza en las universidades públicas nacionales. Metodológicamente, se trata de un estudio teórico, pero también cuenta con evidencias empíricas de prácticas educativas ya realizadas. Entre las reflexiones finales, se destaca la importancia de la pedagogía freireana como una pedagogía contrahegemónica y orientadora para la educación de los pueblos del campo, de las aguas y de los bosques.

Palabras clave: Pensamiento freiriano. Formación de Docentes del Campo. Educación científica.

\section{Introdução}

Os povos do campo, das águas e das florestas, historicamente, em suas vidas, são marcados por processos de extrema exclusão e de nefastas formas de violências, que estão presentes desde a chegada das caravelas portuguesas. São mais de quinhentos anos de estratégias da classe dominante para perpetuar seus paradigmas de opressão. Essa postura intensifica-se a cada momento histórico da sociedade em que vivemos, desde o feudalismo ao capitalismo; e a dominação sobre os corpos, as culturas e as identidades tem prevalecido para manter as formas de existência dos opressores.

Contudo, antagonicamente, esses povos produzem formas de resistência para garantirem suas existências, por mais que as estruturas sociais e políticas nem sempre sejam favoráveis. É em uma postura de contrariedade aos desmandos dos opressores que, por meio das coletividades e da organização social e popular, que diferentes grupos têm conseguido avançar na garantia dos seus direitos.

A partir desse cenário de desafios e de conquistas, em que muitos sujeitos dos diversos territórios compõem as peculiaridades do campo, das águas e das florestas, podemos afirmar que a Educação do Campo é forjada. Sim, forjada, pois é uma conquista que atravessou décadas, séculos para se ter um projeto de educação de acordo com as realidades dos povos, o qual ainda está em permanente construção. Ao estudarmos a história da educação no Brasil, confirmamos a violência cultural e educativa que os colonizadores impuseram aos povos de matriz indígena e africana, a fim de forçarem uma escola de acordo com os preceitos do conservadorismo e do reacionarismo representados pela Coroa e pela Igreja.

No intuito de discutir um elemento da Educação do Campo - neste caso, a formação de professoras e de professores do campo -, temos como questão orientadora das reflexões aqui realizadas: Quais as contribuições do pensamento freiriano diante de uma concepção de formação de docentes que se vincula a um projeto societário contra-hegemônico? Para apontar caminhos em relação a essa questão, objetivamos problematizar as contribuições do pensamento freiriano na formação de professoras/es para atuarem nas escolas localizadas nos territórios do campo, das águas e das florestas. Utilizamo-nos do estudo bibliográfico e documental e da análise da prática docente desenvolvidos nos cursos de formação docente do campo.

Práxis Educativa, Ponta Grossa, v. 16, e2116612, p. 1-17, 2021

Disponível em: < https://www.revistas2.uepg.br/index.php/praxiseducativa 
As discussões, neste texto, estão organizadas a partir dos seguintes tópicos: "Princípios freirianos no ensino de Ciências no contexto da Educação do Campo", no qual discutimos ideias freirianas na Educação do Campo a partir de um ensino de Ciências coerente com a realidade dos sujeitos; "Dialogando com Paulo Freire: Educação do Campo e formação de professoras/es", o qual apresenta elementos da vida e do pensamento de Paulo Freire e aspectos constituidores das Licenciaturas em Educação do Campo, com foco específico no curso ofertado no Setor Litoral da Universidade Federal do Paraná (UFPR); e "Práxis Freiriana: temas geradores, investigação temática, problematização e abordagem Ciência, Tecnologia e Sociedade", por meio do qual visamos apresentar possibilidades formativas a partir dos pressupostos da abordagem dialógica que considera a realidade dos sujeitos. Por fim, nas "Reflexões finais", evidenciamos as contribuições da pedagogia freiriana frente às pedagogias hegemônicas na elaboração de uma educação junto aos povos do campo, das águas e das florestas, além de elementos centrais do pensamento de Paulo Freire que fornecem subsídios para a efetivação de uma educação científica e tecnológica coerentes com a realidade dos sujeitos.

\section{Princípios freirianos no ensino de Ciências no contexto da Educação do Campo}

Paulo Freire, o menino que sonhou com outro mundo e que, no seu transformar-se em professor, educador, tornou-se uns dos maiores intelectuais do pensamento brasileiro, mostrou por meio da sua teoria e das suas práticas, isto é, da sua práxis, que a transformação da sociedade não se faz sem a educação. Na sua trajetória, ele produziu seus escritos a partir do intenso diálogo com a realidade na qual se inseriu. Sempre se colocou ao lado daquelas/es e junto a elas/es que mais viviam em situação de vulnerabilidade social, os oprimidos do mundo. Nesse sentido, ressaltamos, de suas obras, o particular compromisso de Freire com as populações que vivem e trabalham nas comunidades rurais.

Povos do campo, das águas e das florestas que experienciam no cotidiano toda a forma de preconceito, de violência e de exclusão social, como o próprio Freire viveu na sua infância. Um vivido de intensos significados, de profundas marcas de uma sociedade desigual, que talvez o provocasse a sonhar com outro mundo, o que o fez ser o que foi e é para a educação e para o povo brasileiro. Freire conta:

\footnotetext{
Em Jaboatão perdi meu pai. Em Jaboatão experimentei o que é a fome e compreendi a fome dos demais. Em Jaboatão, criança ainda, converti-me em homem graças à dor e ao sofrimento que não me submergiam nas sombras da desesperação. Em Jaboatão joguei bola com os meninos do povo. Nadei no rio e tive "minha primeira iluminação": um dia contemplei uma moça despida. Ela me olhou e se pôs a rir [...]. Em Jaboatão, quando tinha dez anos, comecei a pensar que no mundo muitas coisas não andavam bem. Embora fosse criança comecei a perguntar-me o que poderia fazer para ajudar aos homens. (FREIRE, 1979, p. 9).
}

E foi o que Paulo Freire fez. Após formar-se em Direito, abandonou a carreira de advogado e dedicou-se à educação, à alfabetização de adultos do Nordeste, em uma realidade que produziu as condições materiais para a elaboração das suas ideais. Como resultado do seu engajamento, foram alfabetizadas/os mais de 300 trabalhadoras/es em 45 dias. Prática que impressionou a população e se espalhou por todo o país, visto que o Governo Federal da época apoiou essa iniciativa. Assim, nos anos de 1963 e 1964, foram desenvolvidos diversos cursos de formação de coordenadoras/es para multiplicarem esse processo de alfabetização. No entanto, com a possibilidade da ampliação desse trabalho e de um projeto de intensificação por intermédio dos círculos de cultura, ele foi interrompido pela Ditadura Militar e Civil que se instalou no Brasil (BARBOSA, 2015). Para Freire, 
[...] um golpe de Estado (1964) que não só deteve todo este esforço que fizemos no campo da educação de adultos e da cultura popular, mas também levou-me à prisão por cerca de 70 dias (com muitos outros, comprometidos no mesmo esforço). Fui submetido durante quatro dias a interrogatórios, que continuaram depois no IPM do Rio. Livrei-me, refugiando-me na Embaixada da Bolívia em setembro de 1964. Na maior parte dos interrogatórios a que fui submetido, o que se queria provar, além de minha "ignorância absoluta" (como se houvesse uma ignorância ou sabedoria absolutas; esta não existe senão em Deus), o que se queria provar, repito, era o perigo que eu representava. Fui considerado como um "subversivo internacional", um "traidor de Cristo e do povo brasileiro", "Nega o senhor - perguntava um dos juízes - que seu método é semelhante ao de Stalin, Hitler, Perón e Mussolini? Nega o senhor que com seu pretendido método o que quer é tornar bolchevique o país?...”. (FREIRE, 1979, p. 10).

Diante desse cenário, Paulo Freire foi exilado, expulso do Brasil; contudo, sua saída não significou cessar o sonho de transformar o mundo junto à educação. Continuou seus ensinamentos em outros países, como no Chile e na Nicarágua, na América Latina; em Guiné Bissau e em São Tomé e Príncipe, na África; na Suíça, na Europa; e, também, atuou nos Estados Unidos. Freire regressou ao Brasil em 1980 (BARBOSA, 2015). Esses diversos contextos vividos por Freire constituíram o comprometido educador que ele se tornou, pois as vivências são as bases do seu pensamento. Suas ideias romperam fronteiras e fortaleceram-se em diferentes territórios, presentes em todos os continentes.

Diante dessa breve contextualização da vida de Paulo Freire, situamos no âmbito da Educação do Campo o pensamento desse educador, o qual tem grande relevância teórico-prática; e, de maneira não óbvia, as abordagens teórico-metodológicas do Ensino de Ciências tiveram influência de sua obra, as quais, hoje, são adotadas em muitos cursos de Licenciatura em Educação do Campo na área de Ciências da Natureza no Brasil. Nesse sentido, quando nos referimos ao ensino de Ciências e à Educação do Campo, podemos afirmar que é um movimento recente desse diálogo. O pensamento freiriano é o grande unificador dos diálogos que visam o pensamento crítico e libertador de consciências, comprometidos com um ensino de Ciências construído com princípios freirianos à luz das exigências teórico-práticas da Educação do Campo. Ora, uma educação científica para os povos do campo, das florestas e das águas que objetive

[...] a colocação do conhecimento científico a serviço da vida, da transformação das condições de profunda desigualdade e injustiça vigente no campo brasileiro, decorrente da intensificação e agravamento do modelo agrícola hegemonizado pelo agronegócio, que cada vez mais intensamente desterritorializa os sujeitos camponeses, em busca das terras em seu domínio, para nelas implantar mais monoculturas, promover mais destruição ambiental, utilizar mais agrotóxicos, promover mais devastação da natureza e destruição da biodiversidade, da água, do solo... e obter mais lucro! Qual a relação das Ciências da Natureza com esses processos? Em que medida os conteúdos do ensino de Biologia, de Química, de Física relacionam-se com essas questões? Em que medida os conteúdos trabalhados com a juventude camponesa nas escolas do campo contribuem para ampliar sua compreensão sobre as tensões e contradições presentes na realidade? Que possibilidades de intervenção sobre esta realidade e sobre seu próprio destino essa educação lhes franqueia? (MOLINA, 2014, p. 17).

Diante desses desafios, Brick et al. (2014), em um trabalho intitulado Paulo Freire: interfaces entre Ensino de Ciências Naturais e Educação do Campo, refletem a respeito do campo de pesquisa na área da educação científica de modo a apresentar as convergências e as possibilidades formativas para as licenciaturas em Educação do Campo, sob a tríade ensino, pesquisa e extensão. Para os autores, é preciso aliar as pesquisas da área do ensino de Ciências aos registros culturais da realidade das comunidades dos sujeitos, por meio de documentários, de textos e de diálogos gravados em áudio feitos junto às comunidades, entre outras produções.

Práxis Educativa, Ponta Grossa, v. 16, e2116612, p. 1-17, 2021

Disponível em: < https://www.revistas2.uepg.br/index.php/praxiseducativa 
Tais ações têm como objetivo fazer com que a comunidade acadêmica conheça, compreenda e valorize as práticas culturais e cotidianas que são próprias às/aos quilombolas, indígenas, caiçaras, às/aos pescadoras/es artesanais e agricultores familiares e que, portanto, possibilite pensar abordagens teórico-metodológicas voltadas a esses sujeitos distintos. Ademais, esse processo de reconhecimento do contexto local previne que as universidades imponham ideias e valores que não contribuam para a valorização de hábitos e de saberes culturais tradicionais, ou que leve ao que Paulo Freire denominou de invasão cultural, sendo esta "[...] a penetração que os invasores fazem no contexto cultural dos invadidos, impondo a eles sua visão do mundo, enquanto lhes freiam a criatividade, ao inibirem sua expansão" (FREIRE, 1987, p. 149).

Obviamente essa invasão à qual se refere Freire tem uma dimensão mais ampla e abrange, sobretudo, a colonização europeia nos continentes africano e latino-americano. Contudo, quando se trata de conhecimentos científicos, não científicos e valores culturais, pode-se dizer que as escolas, as universidades e as igrejas dessas ex-colônias, como o Brasil, trazem consigo referências da cultura europeia que não são coincidentes com as culturas indígena e quilombola. Logo, é preciso ter consciência dessas diferenças para que não ocorra uma segunda invasão cultural.

Para além dessa dimensão, Brick et al. (2014) enfatizam a necessidade de promover eventos que reúnam movimentos sociais, como os sujeitos do campo, das águas e das florestas, e as/os professoras/es e pesquisadoras/es para estreitar o entendimento do papel da ciência e da tecnologia e o seu ensino nas escolas do campo. Segundo os autores:

\footnotetext{
Nesses eventos é mister a participação dos movimentos sociais que propiciem aos docentes - principalmente aqueles que tem uma trajetória acadêmica marcada pela fragmentação disciplinar de busca por assepsia filosófica e política, resquícios de um positivismo ainda vivo na prática - um mergulho nas origens e nos princípios da Educação do Campo, aos quais devem estar voltadas [às] ações relacionadas à Educação em Ciências. (BRICK et al., 2014, p. 52).
}

Esse mergulho visa principalmente orientar e direcionar as matrizes curriculares oficiais de modo a adequá-las às necessidades e às características dos sujeitos. Nesse sentido, é fundamental repensar conhecimentos ou temas geradores de ensino, bem como processos formativos das/os professoras/es da Educação Básica ao Ensino Superior, sobretudo em razão do condicionamento acadêmico disciplinar. Ora, o "senso comum pedagógico" precisa ser problematizado a partir do modo como o ensino de Ciências tem sido praticado e, sobretudo, em relação aos seus resultados. Diante disso, espera-se que os docentes se conscientizem da necessidade de articular o ensino de Ciências à realidade local. É a respeito desse aspecto que trataremos a seguir.

\section{Dialogando com Paulo Freire: Educação do Campo e a formação de professoras/es}

O legado freiriano permeia e está presente em muitas experiências educativas no Brasil, por mais que, na atualidade, tenha sofrido intensas críticas dos setores mais reacionários e conservadores da sociedade brasileira. O seu ideário de educação e de formação humana transcendeu décadas e teorias pedagógicas, e, assim, tornou-se uma das bases da Educação do Campo. Esta, de acordo com a legislação educacional vigente, se faz presente tanto na Educação Básica quanto no Ensino Superior, sendo este último o foco das análises e das reflexões que seguem, a partir das Licenciaturas em Educação do Campo no Brasil. Assim, na sequência, apresentamos as contribuições dos cursos de formação de professoras/es do campo a partir de um trabalho educativo dialógico, crítico e comprometido com a transformação da realidade.

Ao problematizarmos a formação de professoras/es, pretendemos apontar as possibilidades de uma educação que se vincule a um projeto societário contra-hegemônico. Nesse 
caso, a Educação do Campo, enquanto o inédito-viável, conforme notas apresentadas por Ana Maria Freire em Pedagogia da esperança (FREIRE, 1992). Para a autora, "[...] é na realidade uma coisa inédita, ainda não claramente conhecida e vivida, mas sonhada e quando se torna um 'percebido destacado' pelos que pensam utopicamente, esses sabem, então, que o problema não é mais um sonho, que ele pode se tornar realidade" (FREIRE, 1992, p. 206).

Como experiência histórica, podemos afirmar que a Educação do Campo se constitui a partir de diversos acúmulos de conhecimentos em relação à educação junto aos trabalhadores e às trabalhadoras, neste caso específico aos povos do campo, das águas e das florestas. Assim, destacamos as matrizes/raízes que compõem os pressupostos políticos, pedagógicos e filosóficos que constituem a Educação do Campo no Brasil, pelo menos nesse primeiro momento de sua produção como período de constituição das suas bases, de reafirmação nos territórios e de ocupação dos espaços institucionais. Devido ao seu fortalecimento e a sua expansão, a concepção de Educação do Campo vem agregando outros sujeitos, outras histórias, outras pedagogias; enfim, outras formas de produzir conhecimento, educação e escola.

Como processo de "[...] associação e de teorização de práticas educativas protagonizadas pelos trabalhadores ao redor do mundo, e conduzidas (na teoria e na prática) desde seus objetivos da classe para construção de novas relações sociais de caráter socialista” (FREITAS, 2015, p. 7), temos, como primeira matriz, a Pedagogia Socialista do período entre 1917 e 1931', com os pioneiros Krupskaya (2017), Pistrak (2009, 2015, 2018) e Shulgin (2013).

Esse conjunto de teorias e de práticas produzidas no contexto russo pôde ser materializada na realidade brasileira a partir da outra matriz da Educação do Campo, a Pedagogia do Movimento dos Trabalhadores Rurais Sem Terra (MST), "[...] como um esforço particular de construção histórica concreta da pedagogia socialista. O MST tem buscado vincular a educação às lutas pela transformação social, desde a realidade atual do campo [...]" (CALDART, 2017, p. 263). Por fim, a terceira matriz, a Educação Popular, tem Paulo Freire como sinônimo de uma coletividade de educadoras/es que atuaram e atuam em diversos contextos urbanos e rurais. Ao construir processos educativos para além da leitura das letras e dos números, da escolarização em si, essa coletividade realiza uma prática vinculada à realidade, produz uma leitura engajada, conforme definido por Freire, de leitura de mundo (PAULA, 2019).

As matrizes são os fundamentos do que produzimos, conforme Caldart $(2008,2012)$ e Munarim $(2008$, 2011), denominado de Movimento Nacional de Educação do Campo, expressão de muitas lutas para garantir educação, escola e universidade de acordo com a realidade, de forma a respeitar as singularidades dos sujeitos, que seja em oposição às práticas da educação rural, uma forma de materialização do Paradigma do Capitalismo Agrário (ABRAMOVAY, 2007). Assim, a realidade que forjou o Movimento Nacional de Educação do Campo

[...] é de violenta desumanização das condições de vida no campo. Uma realidade de injustiça, desigualdade, opressão, que exige transformações sociais estruturais e urgentes. Os sujeitos da educação do campo são aquelas pessoas que sentem na própria pele os efeitos desta realidade perversa, mas que não se conformam com ela. São os sujeitos da resistência no e do campo: sujeitos que lutam para continuar sendo agricultores apesar de um modelo de agricultura cada vez mais excludente; sujeitos da luta pela terra e pela Reforma Agrária; sujeitos pela luta por melhores condições de trabalho no campo; sujeitos da resistência na terra dos quilombos e pela identidade própria desta herança; sujeitos da luta pelo direito de continuar a ser indígena e brasileiro, em terras demarcadas

\footnotetext{
${ }^{1}$ Ver Freitas (2017).
} 
e em identidades e direitos sociais respeitados; e sujeitos de tantas outras resistências culturais, políticas, pedagógicas. (CALDART, 2004, p. 152).

Os efeitos das desigualdades sociais - que historicamente, no campo, têm tomado grandes proporções na vida dos sujeitos em relação às condições de construção de possibilidades para romper com as dinâmicas sociais que produzem e aprofundam tais desigualdades - produziram unidade entre a diversidade de sujeitos que constituem os territórios do campo, das águas e das florestas. Aquelas e aqueles que têm um modo singular de relação com a natureza e o trabalho, tais identidades abarcam diversos contextos socioculturais em que esses sujeitos vivem e trabalham, os quais são reconhecidos como

[...] assalariados rurais temporários, posseiros, meeiros, arrendatários, acampados, assentados, reassentados atingidos por barragens, pequenos proprietários, vileiros rurais, povos das florestas, etnias indígenas, comunidades negras rurais, quilombos, pescadores, ribeirinhos e outros mais. Entre estes, há os que estão vinculados a alguma forma de organização popular, outros não. São diferentes gerações, etnias, gêneros, crenças e diferentes modos de trabalhar, de viver, de se organizar, de resolver os problemas, de lutar, de ver o mundo e de resistir no campo. (PARANÁ, 2006, p. 27).

Oriundas de uma política pública educacional, as Licenciaturas em Educação do Campo no Brasil são reivindicadas a partir da luta dos sujeitos do campo, das águas e das florestas, as quais, de alguma forma, compõem, direta ou indiretamente, o Movimento Nacional de Educação do Campo, a fim de garantir o direito de acesso ao e de permanência no Ensino Superior - neste caso, na formação de professoras e de professores para atuarem nas escolas desses territórios.

Povos que lutam por uma formação que contemple dimensões para além do domínio pedagógico, dos conhecimentos científicos desarticulados com a realidade; que buscam processos que assumam a totalidade e as contradições presentes na vida, nas escolas, na sociedade.

\footnotetext{
A discussão acerca da formação de educadores na perspectiva da Educação do Campo exige que seja explicitado o projeto de sociedade, de campo e escola que se quer construir. Com esse conjunto é possível definir qual o perfil e que formação é necessária para fundamentar práticas coerentes com os princípios e valores que estruturam essa concepção. (MOLINA; ANTUNES-ROCHA, 2014, p. 225).
}

Contudo, a criação das Licenciaturas só foi possível em virtude de um processo histórico de engajamento e de lutas pelo acesso ao Ensino Superior junto ao Estado. O marco político dessas conquistas foi o Programa Nacional de Educação na Reforma Agrária (Pronera), criado em 1998 e vinculado ao Ministério do Desenvolvimento Agrário. Entretanto, foi sonhado, pensado e articulado no I Encontro Nacional das Educadoras e Educadores da Reforma Agrária em 1997. O Pronera possibilitou e ainda possibilita a formação de muitos sujeitos.

Todavia, com a Política Nacional de Educação do Campo, instituída pelo Decreto No 7.352, de 4 de novembro de 2010, provocou a criação do Programa Nacional de Educação do Campo (Pronacampo), o qual tem linhas de ação para a efetivação dessa política, a saber: I - Gestão e Práticas Pedagógicas (Programa Nacional do Livro Didático - PNLD Campo; Programa Nacional Biblioteca da Escola - PNBE Temático; Mais Educação Campo); II - Formação Inicial e Continuada de Professores (Formação Inicial e Continuada de Professores, Escola da Terra); III Educação de Jovens e Adultos e Educação Profissional (EJA Saberes da Terra, Programa Nacional de Acesso ao Ensino Técnico e Emprego); e IV - Infraestrutura Física e Tecnológica (Construção de Escolas, Inclusão Digital, Programa Dinheiro Direto na Escola - PDDE - Campo, PDDE Água e Esgoto Sanitário, Luz para Todos na Escola, Transporte Escolar).

Por meio da linha "Formação Inicial e Continuada de Professores", instituiu-se o Programa de Apoio à Formação Superior em Licenciatura em Educação do Campo (Procampo), o qual 
garantiu a criação dos cursos de Licenciatura em Educação do Campo, vinculados ao Ministério da Educação (MEC). Salientamos que a conjuntura política da criação desse programa é bem diferente do momento de constituição do Pronera.

\begin{abstract}
Pelo percurso de construção dos marcos legais e dos programas, [...], esperava-se um instrumento de materialização da política de Estado para a Educação do Campo, a partir das concepções definidas no Decreto $n^{\circ}$ 7352. Porém, o Pronacampo, apresentado como sendo esta política, ficou muito aquém e em alguma medida retrocede em relação às conquistas obtidas no plano legal e em especial ao proposto pelo Decreto de 2010. Vale destacar que a presença dos movimentos e organizações sociais em reuniões que debateram a construção do Programa na Comissão Nacional de Educação do Campo (CONEC/MEC), não conseguiu assegurar que ele atendesse a expectativa proposta pelo Decreto. Muitas ações incluídas no Pronacampo não passaram pelo debate na CONEC, sendo resultado de discussões internas ao governo, e seguindo a lógica das orientações políticas que vêm sendo explicitadas em políticas públicas apresentadas à sociedade, a exemplo do Pronatec. (FONEC, 2012, p. 17).
\end{abstract}

Mesmo diante de conjunturas políticas contraditórias, as Licenciaturas em Educação do Campo vêm se territorializando no âmbito da universidade pública, com cursos ofertados em todo o território brasileiro, conforme mostra a Figura 1, e conquistando seu espaço na qualidade de um projeto de formação de professoras/es que objetiva atender à realidade específica dos sujeitos do campo, das águas e das florestas. De forma geral, o intuito é "[...] formar e habilitar profissionais para atuação nos anos finais do Ensino Fundamental e Ensino Médio, por área de conhecimento e também para a gestão de processos educativos escolares e processos educativos comunitários" (MOLINA; HAGE, 2016, p. 806).

Figura 1 - Territorialização das Licenciaturas em Educação do Campo no Brasil

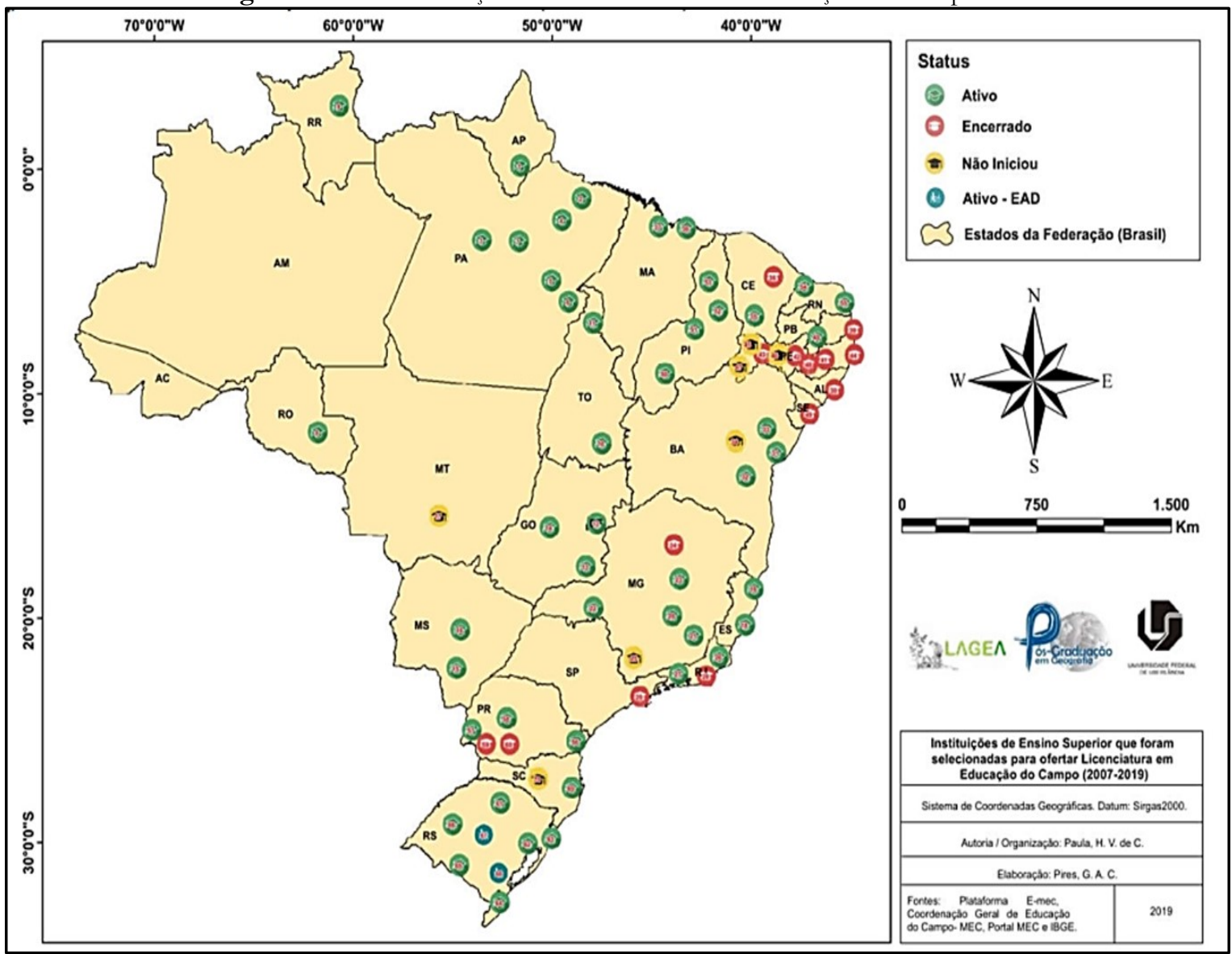

Fonte: Paula (2020, p. 153). 
Nesse contexto, educadoras/es do Setor Litoral da UFPR, juntamente aos sujeitos do campo, das águas e das florestas da região do litoral paranaense, pleitearam e foram contemplados, por meio do Edital SESU/SETEC/SECADI n ${ }^{\circ} 2 / 2012$, para a criação do curso de Licenciatura em Educação do Campo: Ciências da Natureza (Lecampo). No entanto, o seu funcionamento iniciou-se no ano de 2014, após a contratação, via concurso público, das/os professoras/es efetivas/os que iriam trabalhar nesse curso.

A Lecampo, como outros cursos da mesma natureza, tem como um dos seus princípios a organização curricular por intermédio do Regime de Alternância ${ }^{2}$. Sua organização curricular e pedagógica possui tempos diferenciados de formação: o Tempo Universidade (momento de aulas com as/os professoras/es e demais atividades a partir da universidade); e o Tempo Comunidade (momento de diálogo com a realidade, com as comunidades de origem dos estudantes). Essa forma de organização oportuniza o acesso à universidade, sem deixar as suas comunidades; ela parte dessa realidade como estratégia de apropriação de conhecimentos mediante o diálogo entre $\mathrm{O}$ conhecimento científico, o conhecimento da experiência e a realidade concreta.

A organização curricular em regime de alternância, composta por períodos de
aprendizagem integrados entre Tempo Escola, nas Universidades públicas e Tempo
Comunidade, que ocorre nas áreas rurais de origem destes educandos, objetiva não só
evitar que o ingresso de jovens e adultos na educação superior reforce a alternativa de
deixar de viver no campo, bem como objetiva promover a articulação entre educação e
a realidade específica destas populações, possibilitando uma leitura crítica que, a partir
dessa realidade, seja capaz de perceber as determinações sociais que assim a produzem,
considerando a totalidade maior que a contém. (MOLINA; ANTUNES-ROCHA, 2014,
p. 230).

Outra característica relevante na organização da Lecampo é a Itinerância. As/Os professoras/es se deslocam aos territórios, até as comunidades onde são realizadas as aulas do Tempo Universidade. O curso constituiu turmas fora dos muros da universidade; no entanto, sem negar o acesso aos espaços ofertados pela estrutura do Setor Litoral, como a biblioteca, os laboratórios de informática e as ciências, entre outros. As turmas têm aulas nos finais de semana ou em etapas concentradas; e a organização coletiva entre docentes e discentes produz o calendário das atividades de ensino a serem realizadas a cada semestre.

As turmas, em uma estratégia de auto-organização, escolhem nomes para autodenominarem-se. Tal processo objetiva vivenciar, nos seus itinerários formativos, a construção da identidade coletiva da turma. Atualmente, várias turmas concluíram sua trajetória formativa, como a turma Albert Einsten (2014-2018), a qual teve aulas em etapas concentradas na Escola Latino Americana de Agroecologia (ELAA), localizada no Assentamento Contestado, município da Lapa-PR; e outras estão em processo, as quais tiveram aulas nos fins de semana: turma Flor do Vale (2014-2018), com aulas no Centro Comunitário do município de Cerro Azul-PR; turma Guará (2015-2019), com aulas nas dependências do Setor Litoral em Matinhos-PR e momentos específicos de aulas nos territórios dos estudantes, como nos municípios de Antonina, Morretes e Guaraqueçaba; turma Paulo Freire (2015-2019), com aulas na Comunidade de Remanescentes Quilombolas João Surá, no município de Adrianópolis-PR. Já as turmas atuais têm aulas com etapas curtas no Setor Litoral: turmas Sementes Nativas (2017), Sepé Tiaraju (2018), Chico Mendes (2019) e turma 2020.

\footnotetext{
${ }^{2}$ Ver Molina e Sá (2012, p. 468).
} 
Diante do exposto, em relação às características da Lecampo, apresentamos elementos da Proposta Pedagógica do curso que evidenciam aproximações com os pressupostos freirianos.

O curso baseia-se na proposta de Paulo Freire de resgate do humano como sujeito de si e de sua própria educação. $O$ pensador argumenta em defesa da educação, como dinamizadora do processo de mudança, firmando as bases da aprendizagem: capacidade de autorreflexão como desenvolvimento da consciência crítica, que reorganiza as experiências vividas, transformando a realidade. A aprendizagem modifica o homem que, ao mesmo tempo em que se renova, mantém a própria identidade. (UFPR, 2012, p. 6).

É explícito o alinhamento teórico pedagógico com os ideários de uma educação libertadora, a qual busca fortalecer os processos de autonomia, de formação humana crítica comprometida socialmente. Para esse projeto de formação de professoras/es do campo, a Lecampo tem os seguintes objetivos que se relacionam a uma pedagogia libertadora e às vivências de conscientização social:

Promover uma pedagogia da alternância com um currículo vivo [...]; Proporcionar em conjunto com o educador uma escola formadora de sujeitos articulados a um projeto de emancipação humana; Possibilitar um espaço de valorização dos diversos saberes constituídos a partir da realidade do educando; Mobilizar e legitimar princípios e metodologias emancipatórias a partir da Educação do Campo [...]; Adensar a práxis socialmente envolvida nas formações dos professores do campo [...]; Implementar espaços coletivos de problematização das questões cotidianas acerca da exclusão histórica das pessoas do campo à educação e como consequência a exclusão a outros direitos e espaços no mundo do trabalho do campo e nele viver e produzir organicamente; Refletir e reagir coletivamente ante a histórica estrutura fundiária do latifúndio, da monocultura, do agronegócio, da expulsão da terra [...]; Valorizar os conhecimentos [que os] educandos, núcleos familiares e comunidades possuem [para estabelecer] um diálogo permanente com os saberes produzidos nas diferentes áreas do conhecimento; Considerar o trabalho como princípio educativo e vinculado a existência humana na relação com a natureza [...]. (UFPR, 2012, p. 16-17).

Esses objetivos visam indicar caminhos a serem percorridos na trajetória formativa de cada estudante. Pressupõem metodologias de trabalho que respeitem e envolvam as comunidades de origem de cada sujeito que conquista o acesso à Lecampo. Inspira às/aos professoras/es formadoras/es do curso o horizonte de transformação dos sujeitos a partir dos e junto aos conhecimentos prévios dos estudantes, isto é, aos conhecimentos ancestrais e tradicionais, da experiência, do vivido, com base na relação com a natureza e o trabalho. Cabe assim à/ao docente do curso possibilitar às futuras/os professoras/es que vão atuar em processos educativos escolares e não escolares no contexto do campo, das águas e das florestas, “[...] o exercício do processo de ação-reflexão-ação na prática, fortalecendo a sua formação numa perspectiva emancipatória, [...] em uma articulação entre teoria e prática” (UFPR, 2012, p. 24). Conforme Molina (2017, p. 590) “[...] essas Licenciaturas [...] são planejadas considerando-se a luta de classes no campo brasileiro e colocando-se como parte e ao lado do polo do trabalho, assumindo e defendendo a educação como um direito e um bem público e social".

A posição de classe dos cursos de Licenciatura em Educação do Campo demarca um outro processo de formação de professoras/es no Brasil, o qual se materializa em um curso que, no seu projeto original, assume matrizes/raízes formativas que visam a uma concepção de ser humano comprometido com o rompimento da lógica capitalista, com vistas a outra educação e sociedade de acordo com os interesses da classe trabalhadora. "Assume explicitamente em seu projeto político pedagógico original que sua lógica formativa se baseia na imprescindível necessidade de superação da sociabilidade gerada pela sociedade capitalista [...]” (MOLINA, 2017, p. 592). 
Pensar a formação docente na perspectiva de superação dos paradigmas hegemônicos tem como finalidade repensar a escola em si, seu conteúdo e sua forma, os quais se perpetuam, no sentido de garantir os ideários da classe dominante, a qual tem definido como projeto de educação uma escola que prepare, formate para o mercado de trabalho, de modo a formar trabalhadoras/es obedientes e submissas/os às diversas maneiras de exploração e de violência.

As escolas do campo, das águas, das florestas, das periferias da sociedade devem ter como tarefa fundamental "[...] promover o diálogo entre os conteúdos científicos a serem ensinados em cada série/ciclo e os contextos socioterritoriais dos educandos, além da ampliação de sua compreensão dos conflitos e tensões presentes nesses territórios (MOLINA, 2017, p. 604). Além disso, devem organizar um trabalho político-pedagógico que vise à emancipação humana e política desses sujeitos a partir dos seus territórios, dos seus modos de vida, das suas identidades individuais e coletivas.

\section{Práxis Freiriana: temas geradores, investigação temática, problematização e a abordagem Ciência, Tecnologia e Sociedade}

Diante das reflexões anteriores, agora procedemos a apresentar os vieses freirianos no ensino de Ciências da Natureza adotados nos cursos de Licenciatura em Educação do Campo no Brasil. Essas abordagens baseiam-se especialmente nas noções de tema gerador, investigação temática, dialogicidade e problematização. Os temas geradores, de modo geral, na perspectiva freiriana, são precedidos pela investigação temática, na qual se lança questionamentos em direção à comunidade local e também escolar para que os educadores apreendam a realidade, a gnosiologia do coletivo local, para que se observem as situações-limites, as condições materiais, sociais, políticas e sociais que limitam o agir e o pensar dos oprimidos, em razão da sua imersão fatalista em uma realidade opressora.

A noção de tema gerador reúne o conjunto ou parte dos problemas e as características existenciais dos grupos sociais locais. O trabalho com o tema gerador supõe que esses grupos tenham um certo nível de consciência coletiva da sua condição como sujeito oprimido (LUTFI; SEABRA; PONTUSCHKA, 1993). Entre os temas geradores emergentes na área de Ciências da Natureza no Brasil na Educação do Campo, temos: a saúde e a qualidade de vida (saneamento, agroecologia, meio ambiente, plantas medicinais, lixo), a energia (barragens, eletricidade, fotossíntese, biodigestores), o solo (estrutura físico-química e biológica), os agrotóxicos (doenças, contaminação dos alimentos, das pessoas, do ar, dos solos e dos rios), a água (disponibilidade e qualidade) (MOLINA, 2017; BARBOSA, 2018). Os temas geradores e os conceitos unificadores apresentados resultam de uma problematização da realidade das/os educandas/os, de situações sociais significativas, as quais emergem de uma prática dialógica, de escuta atenta, pois, "[...] somente por meio do diálogo que implica um pensar crítico, é capaz, também, de gerá-lo" (FREIRE, 1987, p. 83).

Para exemplificar o modo como se tem planejado as aulas de Ciências no contexto da Educação do Campo sob a abordagem teórico-metodológica da investigação temática e do tema gerador, apresentamos, a seguir, o Quadro 1, elaborado por Britto (2017) a partir de um curso de formação de professoras/es. 
Contribuições de Paulo Freire na Educação do Campo: formação de professores/as e o ensino ...

Quadro 1 - Investigação temática e o ensino de Ciências na Educação do Campo

\begin{tabular}{|c|}
\hline Planejamento da aula \\
Fala significativa: \\
"Prefiro trabalhar fora do lote e comprar o alimento do que plantar, pois gasta muito para produzir e tem praga". \\
Contratema: \\
A qualidade de vida camponesa está relacionada à autossuficiência produtiva e à valorização da autonomia \\
sociocultural como prática formativa e inovadora. \\
Conceitos unificadores: \\
Transformação: germinação, fotossíntese, fixação de nitrogênio. \\
Regularidades: DNA do feijão, ciclo reprodutivo, moléculas (água e oxigênio). \\
Energia: energia potencial química, energia luminosa e energia química. \\
Escala: tempo, temperatura.
\end{tabular}

Fonte: Adaptado de Britto (2017).

Como podemos observar, a investigação temática via interação dialógica possibilita a busca pelo conteúdo programático, a delimitação teórico-conceitual (Conceitos Unificadores) para as aulas de Ciências da Natureza no contexto das escolas do campo, em que se objetiva superar as compreensões e as situações limites dos sujeitos (Fala significativa) para levá-los à conscientização da sua condição objetiva (Contratema) e, quiçá, transformá-la.

Para além dos temas geradores, as abordagens Ciência, Tecnologia e Sociedade (CTS), a partir de Freire, têm sido uma alternativa teórico-metodológica para os cursos de Licenciatura em Educação do Campo (BARBOSA, 2018). Os principais expoentes dessa área de pesquisa no Brasil são Angotti e Auth (2001), Auler e Delizoicov (2001) e Santos e Mortimer (2001).

Angotti e Auth (2001) preocuparam-se com a visão fragmentária da realidade tecnocientífica, a qual perpassa as instituições de ensino em todas as suas dimensões, inclusive na formação de professores. Para os autores, a ausência de uma formação global e crítica, que inclua aspectos sociais, éticos e ambientais, somados aos conhecimentos históricos e epistemológicos da ciência, torna ainda mais improvável a mudança das práticas educacionais nas escolas de nível médio brasileiras (BARBOSA, 2015). Na mesma direção, Auler e Delizoicov (2001) buscaram estabelecer parâmetros para a educação científica que interrelacionam as ideias de Paulo Freire aos referenciais teóricos da temática CTS. Para eles, a mitificação da visão positivista da ciência, no que tange ao determinismo, ao salvacionismo científico tecnológico e à superioridade das decisões tecnocráticas, impede que professoras/es e estudantes tenham uma leitura crítica da realidade.

Para além dos aspectos concernentes à formação docente, Santos et al. (2009) desenvolveram materiais didáticos com a inclusão de textos temáticos com a finalidade de provocar a discussão de Aspectos Sociocientíficos (ASC), os quais são elementos sociais, econômicos, políticos e ambientais associados à ciência e à tecnologia. Além disso, há o intuito de aproximar tais assuntos da experiência existencial dos estudantes, de modo a levá-los a uma reflexão a respeito de seus valores e de suas atitudes. Nessa acepção, uma educação com enfoque CTS na perspectiva freiriana buscaria incorporar ao currículo discussões de valores e de reflexões críticas que possibilitassem desvelar a condição humana. Não se trata, portanto, de uma educação contra o uso da tecnologia e nem uma educação para o uso, mas uma educação em que os estudantes possam refletir a respeito da sua condição no mundo frente aos desafios postos pela ciência e pela tecnologia (BARBOSA, 2015).

$\mathrm{Na}$ Lecampo, temos adotado temas sociocientíficos, tais como o problema do tratamento dos resíduos sólidos, o processo de produção de cachaça, a geração de bioenergia com a construção

Práxis Educativa, Ponta Grossa, v. 16, e2116612, p. 1-17, 2021

Disponível em: < https://www.revistas2.uepg.br/index.php/praxiseducativa 
de biodigestores, a mineração e seus efeitos nocivos, a construção de barragens e suas consequências para os povos do campo. A adoção desses temas tem nos proporcionado realizar uma reflexão crítica a respeito da realidade, sobretudo ao considerar a dimensão ambiental, econômica, histórica, social, política e cultural. Os alambiques, por exemplo, são bens culturais do povo brasileiro que carregam uma história de riqueza para os portugueses e donos de engenhos e, ao mesmo tempo, de miséria e de exploração aos africanos trazidos de maneira forçada ao Brasil. Trata-se de um equipamento que produz a cachaça, bebida genuinamente nacional, resultado de um processo de fermentação e destilação do suco da cana-de-açúcar. No âmbito do ensino de Ciências na Educação do Campo, a tecnologia do alambique, a cachaça e o seu processo de produção possibilita-nos, em uma perspectiva problematizadora, compreender os processos bioquímicos e, também, as relações econômicas de exploração e os problemas sociais de dependência e de violência contra as mulheres, por exemplo, causados pelo consumo em excesso de bebidas alcoólicas no Brasil.

A Figura 2 refere-se a uma aula de campo ${ }^{3}$ realizada no ano de 2017 com a turma Flor do Vale, em um alambique localizado na região rural no município de Cerro Azul, a qual ocorreu após o estudo das raízes históricas dos alambiques no Brasil e dos processos físicos, biológicos e químicos envolvidos na fabricação da cachaça.

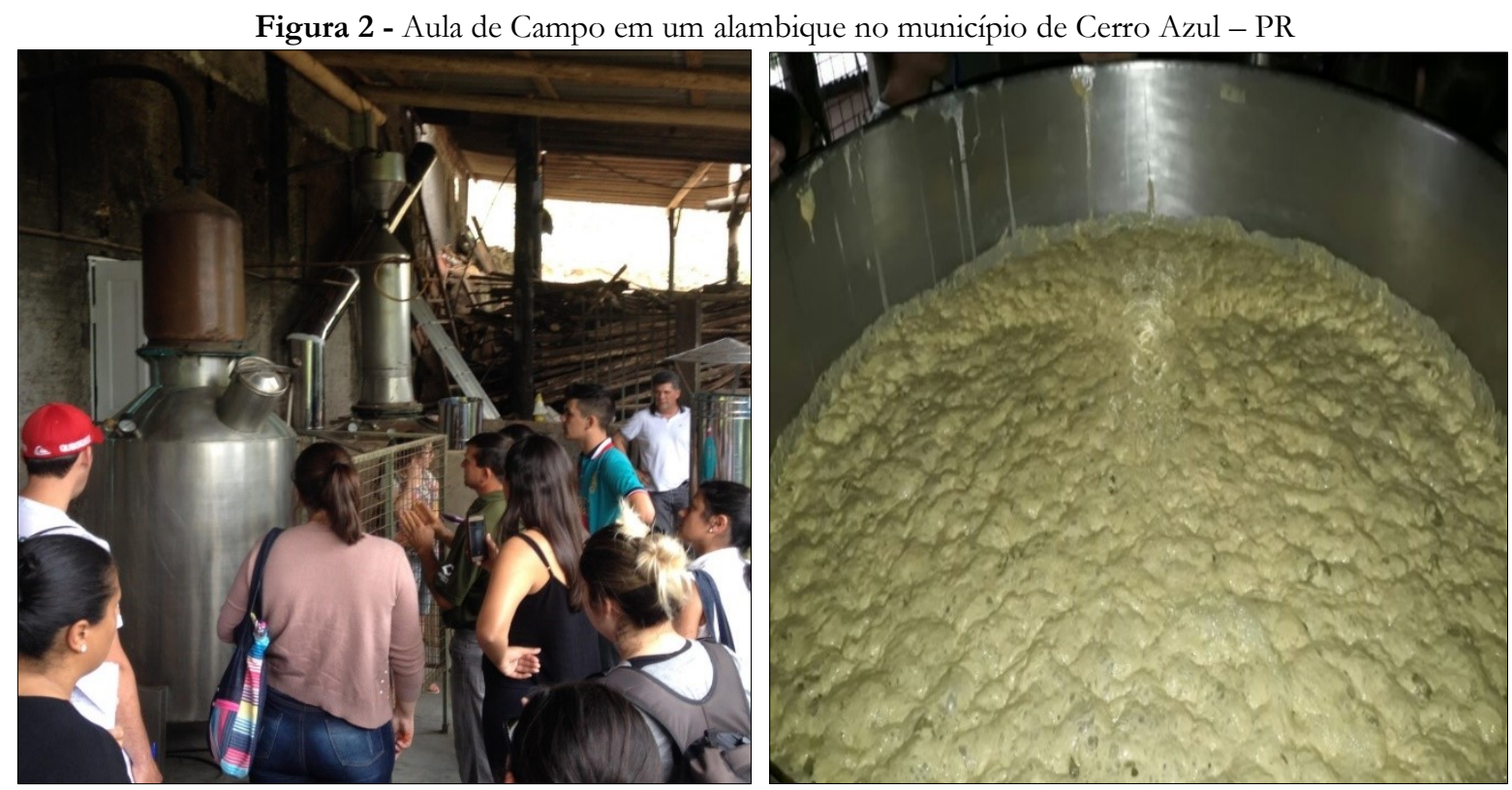

Fonte: Acervo dos autores (2017).

Esse momento propiciou uma experiência fecunda aos estudantes, pois tiveram a oportunidade de objetivar os conhecimentos aprendidos na teoria e, ao mesmo tempo, resgatar memórias ligadas às vivências familiares. Posteriormente, também foram realizadas discussões a respeito das questões sociais e políticas desse bem simbólico do povo brasileiro. Buscou-se, assim, estabelecer relações entre o particular e o universal a partir do contexto local: a produção artesanal nas regiões rurais de Cerro Azul frente à produção em larga escala das indústrias.

\footnotetext{
${ }^{3} \mathrm{O}$ breve relato da prática de ensino respeitou todos os procedimentos éticos, conforme orientações que constam no texto da Associação Nacional de Pós-Graduação e Pesquisa em Educação (ANPEd, 2019), principalmente no que se refere ao respeito ao ser humano, segundo o Art. $1^{\circ}$, inciso III, da Constituição Federal de 1988 (BRASIL, 1988).
} 


\section{Reflexões finais}

A Educação do Campo superou as cercas e os muros que excluíam os povos do campo, das águas e das florestas, das escolas e das universidades públicas. A ocupação desses espaços concretizou-se a partir de um processo intenso de lutas e de resistências dos territórios no enfrentamento das formas dominantes de pensar o mundo e a educação. Diante de cada contexto histórico e político que essas populações viveram e trabalharam, eles conseguiram avançar em políticas que garantam os seus direitos. Contudo, salientamos que houve momentos de recuos, principalmente diante de governos reacionários e neoliberais, os quais não aceitaram a teimosia e os modos de re(existência) das inúmeras comunidades de agricultoras/es familiares, assentadas, acampadas, atingidas por barragens, indígenas, quilombolas, de pescadoras/es artesanais, ribeirinhas, entre outras.

Frente a esses contextos é que os cursos de Licenciatura em Educação do Campo são efetivados nas universidades, a partir de intensa pressão por parte dos movimentos e das organizações sociais e populares, com o intuito de garantir o acesso dos sujeitos que historicamente tiveram esse direito negado pelo próprio Estado. Os cursos dessa natureza de vínculo orgânico com os territórios e as identidades coletivas têm demonstrado ao conjunto das universidades públicas, de modo mais particular aos cursos de formação de professoras/es, outras formas e outros conteúdos a serem desenvolvidos, experienciados nas trajetórias formativas, em processos de intenso diálogo com/a partir da realidade dos sujeitos. É nesse horizonte que os pressupostos freirianos se tornaram o alicerce das práticas educativas realizadas a partir da Educação do Campo, por mais que nem sempre esteja presente no cotidiano, o ideário de uma educação libertadora e crítica tem raízes em Paulo Freire.

No que tange ao Ensino de Ciências na Educação do Campo, podemos destacar, mediante contribuição da pedagogia freiriana, a ampliação e a mudança no rol de conhecimentos das aulas de Ciências que geralmente ocorrem nas escolas urbanas. Essa mudança e essa ampliação devemse, sobretudo, à investigação temática e à problematização das realidades dos educandos. A aula, nesse caso, não se baseia em um livro didático com conteúdos abstratos e pré-definidos, mas, sim, em uma interação dialógica concreta que parte da realidade imediata dos estudantes.

A busca pelo conteúdo programático assinalado por Freire (1987) se refere a esse diálogo franco com a comunidade, em que todos se põem e não se impõe, e a partir do qual emergem os temas de ensino. Um segundo aspecto que convém salientarmos trata-se do viés totalizante e interdisciplinar das aulas de Ciências na Educação do Campo. Ora, os temas geradores exigem o conhecimento de diversas disciplinas para que o estudante tenha uma compreensão adequada da situação considerada. Isso ocorre em razão da natureza dos temas de estudo, os quais se relacionam aos aspectos da vida dos sujeitos, diferentemente das abordagens teórico-conceituais prescritas nos livros didáticos.

Nesse sentido, aprender Ciências torna-se algo mais complexo e abrangente. Complexo por envolver diversas dimensões da realidade, e abrangente por proporcionar uma visão de totalidade da Ciência em sua relação com a sociedade, que a torna em uma educação crítica. Esse modo de ensinar e aprender é totalmente oposto às aulas tradicionais de transmissão/reprodução de conceitos abstratos. Essa constatação leva-nos à terceira contribuição fundamental da pedagogia freiriana ao ensino de Ciências, a saber: o seu alto potencial para promover uma aprendizagem que tenha significado e sentido.

No Brasil, é notório, e os programas de avaliação oficiais nacionais e internacionais demonstram, que grande parte dos estudantes da Educação Básica e do Ensino Superior apresentam dificuldades em aprender Ciências, particularmente Química e Física. E embora não

Práxis Educativa, Ponta Grossa, v. 16, e2116612, p. 1-17, 2021

Disponível em: < https://www.revistas2.uepg.br/index.php/praxiseducativa 
tenhamos dados oficiais, a nossa experiência tem nos mostrado que os sujeitos do campo, das águas e das florestas, de modo aparente, completamente alheios aos conhecimentos e às práticas científicas, se veem sujeitos capazes de aprender e de dizer a sua palavra, quando relacionamos os conceitos científicos às suas realidades.

Posto isso, consideramos que o ideário de mundo e de educação elaborado por Paulo Freire e demais educadoras/es fortaleceu o movimento de uma pedagogia libertária que assume o Ser Humano e a realidade como centralidades dos processos de ensino e de aprendizagem, de modo que, na apropriação do conhecimento científico, assegurado pelas escolas e pelas universidades públicas, o princípio do respeito e do diálogo com a diversidade de conhecimentos tradicionais e ancestrais, associados às experiências e às vivências dos sujeitos, sustente as práticas educativas realizadas pelas/os professoras/es das escolas do campo, das águas e das florestas. Em síntese, a posição em assumir teorias e práticas contra-hegemônicas são essenciais para o fortalecimento dos territórios a partir da Educação do Campo.

\section{Referências}

ABRAMOVAY, R. Paradigmas do capitalismo agrário em questão. São Paulo: Hucitec, Campinas: Edusp, 2007.

ANGOTTI, J. A.; AUTH, M. A. Ciência e tecnologia: implicações sociais e o papel da educação. Ciência \& Educação, Bauru, v. 7, n. 1, p. 15-27, 2001. DOI: https://doi.org/10.1590/S1516$\underline{73132001000100002}$

ANPED. Associação Nacional de Pós-Graduação e Pesquisa em Educação. Ética e pesquisa em educação: subsídios. Rio de Janeiro: ANPEd, 2019.

AULER, D.; DELIZOICOV, D. Alfabetização científico-tecnológica para quê? Ensaio Pesquisa em Educação em Ciências, Belo Horizonte, v. 3, n. 1, p. 1-13, 2001.

BARBOSA, R. G. Educação científica e tecnológica para a participação: Paulo Freire e a criatividade. 2015. (Tese de Doutorado) - Universidade Estadual de Londrina, Londrina, 2015.

BARBOSA, R. G. O Ensino da Física na Educação do Campo: descolonizadora, instrumentalizadora e participativa. Revista Brasileira de Educação do Campo, v. 3, n. 1, p. 177-203, 2018. DOI: https://doi.org/10.20873/uft.2525-4863.2018v3n1p177

BRASIL. [Constituição (1988)]. Constituição da República Federativa do Brasil. Brasília, DF: Senado, 1988.

BRICK, E. M. et al. Paulo Freire: interfaces entre Ensino de Ciências Naturais e Educação do Campo. In: MOLINA, M. C. (org.). Licenciaturas em Educação do Campo e o ensino de Ciências Naturais: desafios à promoção do trabalho docente interdisciplinar. v. I. Brasília: Editora MDA, 2014. p. 23-59.

BRITTO, N. S. A Educação do Campo e a formação docente na área de Ciências da Natureza: caminhos da docência universitária por trilhas da abordagem temática freireana. In: MOLINA, M. C. (org.). Licenciaturas em Educação do Campo e o ensino de Ciências Naturais: desafios à promoção do trabalho docente. v. II. Brasília: Editora UnB, 2017. p. 431-449.

CALDART, R. S. A Escola do Campo em Movimento. In: ARROYO, M. G. et al. (org.). Por uma educação do campo. 2. ed. Petrópolis: Vozes, 2004. p. 87-131. 
CALDART, R. S. Sobre Educação do Campo. In: SANTOS, C. A. (org.). Por uma Educação do Campo: campo - políticas públicas - educação. Brasília: Incra; MDA, 2008. p. 67-86.

CALDART, R. S. Educação do Campo. In: CALDART, R. S. et al. (org.). Dicionário da Educação do Campo. Rio de Janeiro: Escola Politécnica de Saúde Joaquim Venâncio; São Paulo: Expressão Popular, 2012. p. 259-267.

CALDART, R. S. Caminhos para transformação da escola: pedagogia do MST e pedagogia socialista russa. In: CALDART, R. S.; VILLAS BÔAS, R. L. (org.). Pedagogia socialista: legado da revolução russa de 1917 e desafios atuais. São Paulo: Expressão Popular, 2017. p. 260-286.

FONEC. Fórum Nacional da Educação do Campo. Notas para análise do momento atual da Educação do Campo. Brasília: FONEC, 2012.

FREIRE, P. Conscientização: teoria e prática da libertação. São Paulo: Cortez \& Moraes, 1979.

FREIRE, P. Pedagogia do oprimido. Rio de Janeiro: Paz e terra, 1987.

FREIRE, P. Pedagogia da esperança: um reencontro com a pedagogia do oprimido. Rio de Janeiro: Paz e Terra, 1992.

FREITAS, L. C. A pedagogia socialista: devolvendo a voz aos pioneiros da educação russa. In: CALDART, R.; VILLAS BỐAS, R. L. (org.). Pedagogia socialista: legado da revolução russa de 1917 e desafios atuais. São Paulo: Expressão Popular, 2017. p. 233-260.

FREITAS, L. C. Apresentação. In: PISTRAK, M. M. (org.). Ensaios sobre a escola politécnica. São Paulo: Expressão Popular, 2015. p. 7-11.

KRUPSKAYA, N. K. A construção da pedagogia socialista: escritos selecionados. São Paulo: Expressão Popular, 2017.

LUTFI, E. P.; SEABRA, M.; PONTUSCHKA, N. N. Rua e escola: compassos. In: PONTUSCHKA, N. N. (org.). Ousadia no diálogo: interdisciplinaridade na escola pública. São Paulo: Edições Loyola, 1993. p. 143-185.

MOLINA, M. C. Apresentação. In: MOLINA, M. C. (org.). Licenciaturas em Educação do Campo e o ensino de Ciências Naturais: desafios à promoção do trabalho docente interdisciplinar. v. I. Brasília: Editora MDA, 2014. p. 11-21.

MOLINA, M. C. Contribuições das Licenciaturas em Educação do Campo para as políticas de formação de educadores. Educação \& Sociedade, Campinas, v. 38, n. 140, 2017, p. 587-609, 2017. DOI: https://doi.org/10.1590/es0101-73302017181170

MOLINA, M. C.; ANTUNES-ROCHA, M. I. Educação do Campo: história, práticas e desafios no âmbito das políticas de formação de educadores - reflexões sobre o Pronera e o Procampo. Reflexão e Ação, Santa Cruz do Sul, v. 22, n. 2, p. 220-253, jul./dez. 2014. DOI: http://dx.doi.org/10.17058/rea.v22i2.5252

MOLINA, M. C.; HAGE, S. M. Riscos e potencialidades da expansão das Licenciaturas em Educação do Campo. RBPAE, [s. l.], v. 32, n. 3, p. 805-828, 2016. DOI: https://doi.org/10.21573/vol32n32016.68577 
MOLINA, M. C.; SÁ, L. M. Licenciatura em Educação do Campo. In: CALDART, R. S,; PEREIRA, I. B.; ALENTEjANO, P.; FRIGOTTO, G. (org.). Dicionário da Educação do Campo. São Paulo: Expressão Popular, 2012. p. 468.

MUNARIM, A. Movimento Nacional de Educação do Campo: uma trajetória em construção. In: REUNIÃO ANUAL DA ANPEd, 31., 2008, Caxambu. Anais eletrônicos [...]. Caxambu: ANPEd, 2008. Disponível em: http://31 reuniao.anped.org.br/1trabalho/gt03-4244--int.pdf. Acesso em: 10 mar. 2021.

MUNARIM, A. Educação do Campo e políticas públicas: controvérsias teóricas e políticas. In: MUNARIM, A. et al. (org.). Educação do Campo: políticas públicas e práticas pedagógicas. Florianópolis: Insular, 2011. p. 21-38.

PARANÁ. Secretaria de Estado da Educação. Diretrizes Curriculares da Educação do Campo. Curitiba: SEED, 2006.

PAULA, A. P. de. Relações entre Educação do Campo e território: significados da escola da/na ilha para uma comunidade tradicional de Guaraqueçaba no litoral do Paraná. 2019. Tese (Doutorado em Educação) - Universidade Federal do Paraná, Curitiba, 2019.

PAULA, H. V. de C. Territórios e projetos em disputa na institucionalização dos cursos de licenciatura em educação do campo. 2020. Tese (Doutorado em Geografia) - Universidade Federal de Uberlândia, Uberlândia, 2020.

PISTRAK, M. M. A escola-comuna. São Paulo: Expressão Popular, 2009.

PISTRAK, M. M. Ensaios sobre a escola politécnica. São Paulo: Expressão Popular, 2015.

PISTRAK, M. M. Fundamentos da escola do trabalho. São Paulo: Expressão Popular, 2018.

SANTOS, W. L. P. dos; MORTIMER, E. F. Tomada de decisão para ação social responsável no ensino de ciências. Ciência \& Educação, Bauru, v. 7, n. 1, p. 95-111, 2001.

SANTOS, W. L. P. dos et al. Química e sociedade: um projeto brasileiro para o ensino de química por meio de temas CTS. Educación Química, México, v. 3, p. 20-28, 2009.

SHULGIN, V. N. Rumo ao politecnismo (artigos e conferências). São Paulo: Expressão Popular, 2013.

UFPR. Universidade Federal do Paraná. Projeto Pedagógico do Curso de Licenciatura em Educação do Campo - Ciências da Natureza. Setor Litoral. UFPR: Matinhos, 2012.

Recebido em 10/08/2020

Versão corrigida recebida em 06/03/2021

Aceito em 07/03/2021

Publicado online em 16/03/2021

Práxis Educativa, Ponta Grossa, v. 16, e2116612, p. 1-17, 2021

Disponível em: < https://www.revistas2.uepg.br/index.php/praxiseducativa 